\title{
A Wolf at the Gate: \\ The Anti-Carnivore Alliance and the Symbolic Construction of Community
}

Published in Sociologia Ruralis (2003) Vol 43, No 3:309 - 325

Ketil Skogen, Norwegian Social Research, NOVA and Norwegian Institute for Nature Research, NINA ketil.skogen@nina.no Olve Krange, Norwegian Social Research, NOVA olve.krange@nova.no

Department of Sociology and Human Geography University of Oslo

P.O.Box 1096 Blindern

N-0317 OSLO Norway

Telephone: $\quad+4722855257$

Fax:

$+4722855253$

Internet: http://www.iss.uio.no 


\title{
A Wolf at the Gate: The Anti- Carnivore Alliance and the Symbolic Construction of Community
}

\author{
Ketil Skogen and Olve Krange
}

L arge carnivores, and the people who support them, seem to be on the offensive in Europe and North-America. Following decades of protection, and sometimes helped by reintroduction programmes, wolves, lynx and bears are returning to their native range throughout the northern hemisphere. Although officially hailed as a conservation success, this development is definitely not approved of by everyone. Many people living in rural areas do not want them there, and they feel very strongly about it.

The issues at stake are well known: livestock depredation, competition for huntable game, mutilated dogs and potential attacks on people. And while there are very real conflicts between animals and people, the social conflict dimensions are just as evident: these are conflicts between people, involving groups with strongly diverging interests. Some aspects are easy to comprehend; for example those that concern economic interests or leisure activities. Others are perhaps less obvious, but research has shown that they are related to general processes of economic and cultural modernisation, urbanrural tensions and conflicts between hegemonic and subordinate forms of knowledge (Skogen 200I; Kleese 2002; Krange and Skogen 2003).

One striking feature of these conflicts is the way they convey a picture of unified rural communities. An impression is created that these communities stand united in their resistance against intruding vermin, urban romantics who are oblivious to the problems of rural people, and the government's heartless policy of turning once-vital rural areas into game preserves. In fact, the anti-carnivore front seems to be construed as a last line of defence against destructive forces threatening rural life 'as we know it'. But precisely how does this picture emerge?

When seen from outside, the media coverage is of course an important factor. The media generally seek clear-cut images and, if these are about conflict, even better. But the media images are definitely not without a basis in local self-presentations. These are frequently rife with explicit declarations of local solidarity and concord in the face of serious threats. In particular, various organisations that claim to represent rural interests tend to use the resistance against large carnivores for all it is worth. Livestock losses, declining game stocks and lost revenue from hunting leases are often presented as factors that may eventually lead to the demise of whole

Published by Blackwell Publishing, 9600 Garsington Road, Oxford OX4 2DQ, UK 350 Main Street, Malden, MA02148, USA
Sociologia Ruralis, Vol 43, Number 3, July 2003

(C) European Society for Rural Sociology

ISSN 0038-0199 
communities. This will happen not only because of direct economic harm to farms and nature-based businesses, but also because many people will leave because of a deteriorating life quality (being constantly anxious about their own and their children's safety). In sum, this will lead to erosion of the economic and social basis of the affected communities.

A noteworthy aspect of this collective self-presentation is the way the human opponents are pictured by carnivore adversaries, for example in leaflets, on the internet, and in local media. The focus is generally on urban people, who are described as romantics who have lost touch with the basic facts of human existence, or on the state, which shows no compassion for rural people, and is essentially preoccupied with accommodating urban middle-class interests. In Norway, a new term has become a buzzword in the rural discourse on large carnivores (and other aspects of nature conservation): this is the Norwegian phrase 'storsamfunnet', which translates into something like 'society at large'. 'Storsamfunnet' is frequently named as the real culprit; the actor which (through the state) forces small rural communities to live with the carnivore pest, and also to give up traditional land use rights so that urban people can have protected areas as their playgrounds. The term often seems to be used in a deliberate manner; intended to emphasise the uneven balance of power between big institutions and urban centres on the one hand, and small rural communities on the other. Paradoxically, however, ordinary people living in cities are obviously part of 'storsamfunnet', while not even the elites in rural areas seem to be included.

Thus, a powerful rural discourse seems to invoke an image of communities that are under dangerous pressure from hostile external forces. But can it really be this straightforward? Hardly, since 'communities' do not grow out of the earth in any given locality, rural or otherwise. They are actively constructed, and these social constructions serve different functions for different groups (c.f. Cohen ig85, Liepins 2000). Any spatially delimited group (of any size) is necessarily divided along lines of class, education, gender, generation and so on. In rural areas this diversity has obviously increased throughout recent decades. General processes of modernisation have made rural social systems more complex than they used to be. The educational profile of their workforce has changed significantly. Employment in agriculture, resource extraction and related processing industries has declined sharply, whereas middle-class jobs demanding higher education have increased in number. This has been due to an expanding public sector as well as a shift toward a service sector economy which has been quite significant in some rural areas. As demonstrated by research in the UK and USA, social diversification has also increased through in-migration of middle-class people who are not part of the local labour market, but either work from home or commute to urban centres (c.f. Bell I994; Nelson 200I). Consequently, the proportion of the population with higher education has risen quite dramatically. Exchange with urban centres is extensive and the new media have not passed rural areas by. All in all, substantial cultural diversification has taken place, in particular among younger people (Skogen 200I). Accordingly, and not least due to the weakened ties to the utilisation of natural resources, attitudes toward nature and land use issues can hardly remain unaffected. It is just as unlikely that such attitudes are common to all people living in rural areas.

Obviously, then, the strong community images that are invoked through the 
carnivore controversies do not simply reflect common material interests or a monolithic culture. The task here is to explore some theoretical contributions to the concept of community, in order to see how they might help us understand the carnivore conflicts.

\section{The social (or symbolic) construction of community}

'Community' does not have one single meaning, but many. Not only has the term been part of different research traditions throughout the $20^{\text {th }}$ century, it is also used in different ways in different contemporary strands of social theory. However, the most common one may be what Liepins (2000, p.25) calls a 'minimalist approach', meaning that no real definition is provided but that the term is used to denote a "loosely specified sense of social collectivity". Many 'community studies' are studies of what we may term 'local social relations' (Crow and Allan I994), and do not necessarily have any need for a more stringent definition. Many aspects of spatially delimited social systems - rural as well as urban - can be analysed without any sophisticated definition of 'community' - indeed without relating to the term at all. Yet, community as perceived collectivity is also an important research issue. One of the most publicly visible accounts of carnivore resistance is that it is a unifying force in rural communities, underpinning the strong 'sense of collectivity' people in such areas feel. The emphasis on external threats, particularly from 'storsamfunnet' (society at large), and on internal coherence, draws our attention to the issue of community boundaries. How are these boundaries constructed and managed, and by whom?

In our view, the most productive theorising on community boundaries is found within the 'symbolic construction approach' (Liepins 2000), where the standard reference work still seems to be Anthony Cohen's 'The symbolic construction of community' (1985). And with good reason: Cohen argues persuasively that communities as collectivities can have no objective existence. Not only are they social constructions, they are also contested and furnished with very different meanings by different members of any given community. As a basis for our further discussion of the carnivore conflict as an element in the construction of rural communities, we will outline some staple elements in Cohen's theorising.

A simple, yet fundamental, argument in Cohen's work is that the concept of community implies both similarity and difference. Those who are inside share something which makes them different from those who are outside. Therefore community is a relational concept; it is inconceivable except in relation to something which is different from it. However, the internal similarities - common values, beliefs, norms and so on - that constitute the 'inside' of the community are not so definite. Quite the contrary, these 'big' categories tend to be rather elusive, and their content is almost impossible to define with any precision (Cohen I985, p.I5). Given the economic, social and cultural diversity within any community, a total congruence of the interpretations of such concepts is hard to imagine. Community as a social construction is a symbol, and symbols do not simply convey meaning, they are tools that we may use to produce it. If symbols had a very exact content, we would not need them. Indeed, the flexibility of symbols may be their most important quality. So, within limits, the same symbol may express different meanings for different people, while still emphasising internal unity. Diverging interpretations of the same symbols (symbolic expressions of the 
community) do not hinder an effective construction of community. On the contrary, they are a prerequisite for it. A community could not be upheld as a social construction if people could not use the same symbol to express different perspectives, indeed to pursue their own interests (economic or otherwise).

The idea of community demands that 'inside' and 'outside' are clearly separated. This draws attention to the place where the two spheres meet, that is to say, to the boundary. Boundaries do not simply exist; they have to be constructed. In some cases they may be easy to see, even for outsiders, whereas in others they may be almost imperceptible to all except the members of the community itself. Since the boundaries are social constructions, they must be demarcated symbolically. Community itself is a symbol that fills this function of upholding boundaries. As Cohen (1985, p.I5) puts it: "Community is a boundary-expressing symbol. As a symbol, it is held in common by its members; but its meaning varies with its members' unique orientation to it." And further: "The triumph of community is to so contain this [internal] variety that its inherent discordance does not subvert the apparent coherence which is expressed by its boundaries." (ibid).

The issue of constructing boundaries is also a central theme in the writings of Mary Douglas (Douglas 1992, Douglas and Wildavski I982). Her focus on danger (or risk) and blame in this regard seems relevant for our analysis of the carnivore conflict and its function in the symbolic construction of community. Placing the blame for dangers that are seen as threatening a group on those who are thought to deserve it, is an important element in the construction of the boundary between the group and its surroundings. Which dangers we choose to worry about - among all those we could worry about - is generally not based on probability calculations or knowledge of 'facts', nor is it arbitrary. Rather, the dangers that pose the most critical threats to central values or 'moral principles' are generally taken most seriously. And placing the blame for this type of danger on actors outside the community is important to enhance internal cohesion and thus also to construct visible boundaries. Douglas and Wildavsky (I982) take the environmental movement as an example of a 'community' which aims to achieve internal cohesiveness by positing big corporations and their allies in the state apparatus as an outside enemy which is demonised and held up as everything the environmental movement is not. Ironically, the environmental movement itself is often pictured as part of the evil conglomerate confronting people in carnivore areas, and in this context is attributed much the same qualities as the environmental movement ascribes to big business and the state. Together with nature management agencies and biologists, the environmental movement is blamed for posing unacceptable danger to the community (jeopardising the safety of people and domestic animals, and not least the experienced 'life quality'). Together with ignorant city romantics in general, these actors are held up as being responsible for the perils many rural people now have to face.

Rural communities are in the midst of significant social change. Economic modernisation, cultural diversification and increased social and spatial mobility weaken the basis of traditional rural communities that were built around agriculture and resource extraction. Cohen (1985, p. 70) writes that "when the structural base of the boundary becomes undermined or weakened as a consequence of social change, so people resort increasingly to symbolic behaviour to reconstitute the boundary". Why do they do this? Obviously, some changes actually threaten the interests of individuals 
or groups, and resorting to collective resistance efforts is a 'rational choice'. But in addition to this, and affecting even more people, these structural and cultural changes pose a threat to individual and collective identities. The concept of community is inseparably tied to the concept of identity. As Gupta and Ferguson (I997, p.I3) write: “'Community' is never simply the recognition of cultural similarity or social contiguity but a categorical identity that is premised on various forms of exclusion and constructions of otherness." Thus, symbolically reinforcing the community and its boundaries will constitute a resistance effort in the face of threatened individual and collective identities. This resistance may, however, have a different content for different groups within 'the resistance front'; within the community.

Based on material from a large qualitative research project in Østerdalen, Norway, this paper aims to explore the feasibility of analysing the conflicts over large carnivores in this theoretical light.

\section{The Stor-Elvdal study}

The project 'Land use conflicts in rural areas' lasted from 2000 to 2002, and the study's focus was on land use conflicts in rural areas generally (not only those related to carnivores) and the social and cultural factors that constitute axes of differentiation in this field. The study aimed to improve our understanding of the dynamic nature of the social production of meaning regarding land use and resource utilisation.

One locality was the municipality of Stor-Elvdal in Østerdalen in south-eastern Norway. Stor-Elvdal (which means Big River Valley) covers $2 \mathrm{I} 67 \mathrm{~km}^{2}$ of forests and mountains, but the population is only 3 ooo, with about half in the administrative centre Koppang and the rest in small hamlets. The logging and timber industries have always been the pillars of the local economy, but livestock farming also plays a part. Some extremely large forest properties are found in Stor-Elvdal, and most of the owners, who are very wealthy, live in the municipality. Thus, Stor-Elvdal bears the distinct marks of a class society, even today.

Stor-Elvdal is one of very few municipalities that have all the four species of large carnivores native to Norwegian fauna; wolverines, brown bears, lynx and wolves. These animals have been the centre of controversies for a long time. However, the wolves are relative newcomers, and the appearance of two wolf packs a few years ago led to a dramatic escalation of the conflicts. This was part of the reason for selecting Stor-Elvdal as a research site.

In all, 74 interview sessions were conducted in 2000 and 200I, including a total of 88 informants ${ }^{I}$. The interviews were semi-structured, focusing on various aspects of local social relations and on people's relationship to nature and land use. All informants were asked to talk about their background, their family's history in the community, their present life situation in general and their everyday habits, in particular those relating to activities in nature. The interviews also focused on their opinions of the state of their community and their views on nature, land use and related conflicts, such as the one over large carnivores. To make sure that all important topics were covered, a detailed interview guide was employed. Most interviews lasted around two hours, and were recorded for later transcription. The informants were recruited from all age groups from $\mathrm{I} 6$ upwards, and represented a wide range of socioeconomic, educational and socio-cultural groups. Different links to nature use were 
represented, e.g. hunting, grazing, lease of hunting, new forms of nature tourism, general recreation, and lack of any particular interest in nature. The sample was carefully composed so as to provide variation across central sociological variables such as gender, age, education, sector of employment and place of residence. However, within each relevant category, and frequently across them, snowball sampling was employed in order to find the individual informants. To some extent, the transcribed interviews were analysed with the help of a computer programme for qualitative data analysis (NUD*IST).

\section{People and wolves in Stor-Elvdal}

Regarding the carnivore issue, and particularly the recent appearance of wolves, one important finding is that opinions are more varied than one is led to believe by the media. All typical views of the issue are present, including very strong procarnivore attitudes and critical views of modern sheep husbandry. With a very few exceptions, however, people holding such views keep a low profile. There is also a sizeable group which is not engaged in the issue at all, and this 'non-position' appears to be most prevalent among young people. Nevertheless, various degrees of anti-carnivore sentiments seem to be very common.

Varieties of carnivore opposition may be grouped along two axes, one economic/ practical and one cultural. These axes touch each other, but they are far from identical. Three principal groups may be identified; sheep farmers, landowners who lease hunting, and local people with strong ties to traditional land use practices (primarily hunting) and roots in a rural working-class culture. These groups have not always been allies. In fact, conflicts of interest are easily identified, and history is rife with class antagonism as well as trivial skirmishes.

\section{The landowners}

Moose hunting has always been of a certain economic importance for owners of large forest properties in this region, although of course completely overshadowed by timber sales - the basis of tremendous wealth for a few families. Lately, however, some of the largest properties have developed hunting tourism into a more important part of their enterprise, as a response to uncertain times in the timber industry, and a general trend towards commercialisation of outdoor recreation activities. But just when the land owners have established big game hunting as a significant part of their business - enter the wolf, which eats moose and kills hunting dogs. To what degree the moose stocks will actually decline over time as result of wolf depredation is subject to debate. However, there is little doubt that wolves can have a rather dramatic impact in the areas where they concentrate their hunting at a given time. Likewise, wolves do indeed attack and kill dogs. There are quite a few examples of this in Norway, and even more in Sweden. Some dogs have been killed in Stor-Elvdal too. The landowners now fear that the presence of wolves will severely reduce the value of their hunting. There are already reports of hunters who have turned their backs on landowners whose hunting grounds are invaded by wolves.

These landowners belong to an upper class where higher education and cultural capital is becoming increasingly abundant, and they generally express their 
scepticism towards the wolves in a very civil manner. Their focus is, understandably, on the economic losses they suffer themselves, and on the negative impact the wolves will have on the possibility to develop hunting tourism. Some of them seem to have concluded that the wolves will have to go (although they stress that they should definitely be protected in real wilderness areas, while others are more pragmatic about this. A few have seriously considered cooperating with WWF and other outside actors to arrange wolf safaris, but have decided against it, partly as a bad tactical move, and partly as an act of treason against fellow landowners and other suffering community members.

They all agree that their losses should be compensated by the state, however, and one group from Stor-Elvdal has persuaded the Ministry of Environmental Affairs to try out an arrangement by which landowners with 'established wolf packs' actually achieve this. While highly controversial, because it is a step towards establishing property rights to wild animals, it has also provoked a number of smaller landowners in the region who consider it an act of prostitution. However, it may be seen as the type of economic and practical solutions the landowners can live with, and which they have adequate resources to actually bring about.

\section{The sheep farmers}

Sheep husbandry was not a common activity in Stor-Elvdal until the I970s. The land must be considered rather marginal for sheep herding, and it only became economically feasible through heavy subsidies introduced some thirty years ago. The majority of those who have started breeding sheep in Stor-Elvdal seem to be somewhat atypical as Norwegian farmers go. Some of them engage in a diversity of economic activities related to land use and tourism, some are large landowners with sheep herding as a minor side line, some are well-educated people who have made a decision to leave the city behind - and of course some are traditional farmers, but they seem to be a minority. Sheep herding contributes relatively little to the local economy, and few people are involved. Approximately 35 farms have sheep, and of these, only six or seven have sheep herding as their main activity.

The sheep owners' problem with the carnivores is easy to see; their sheep are eaten. As this is obviously an economic problem and causes lots of extra work, and also represents emotional strain that is easy to identify with, the sheep owners' situation has received considerable attention in the national media and in the public debate. The authorities have also concentrated on the problems the carnivores cause sheep herders, since these are related to economic activities, including economic activities that receive government subsidies. Furthermore, farmers are represented by strong organisations that government agencies are accustomed to dealing with.

Sheep farming now receives unprecedented attention in Stor-Elvdal. Some local sheep owners are resourceful people, who often manage to make their voices heard. Now they are also helped by the media focusing on their problems, and not only depicting them as over-subsidised receivers of tax-payers' money. They now see themselves as symbols of rural people's struggle against urban ignorance, and find that many people outside sheep farming also see them in this role.

Very few sheep herders can accept wolves in their area, or in the whole of Norway. Their arguments generally focus on rough grazing as a viable, ecologically 
sound method of meat production, and - as the wolf is not threatened as a species - this should be considered more important than protecting the wolf in areas where such production takes place. However, the way in which this view is articulated varies a great deal. We might say that one extreme is an economic rationalism akin to the perspectives of some large landowners, while the other is a form of 'cultural resistance'. Such cultural resistance is also typical of the working-class hunters, who we will now turn to (Krange and Skogen 2003; see also Willis I977; Scott I990).

\section{The hunters}

A significant proportion of the carnivore adversaries is found among working-class men with a strong attachment to a traditional lifestyle close to nature, particularly through hunting. The concrete issues these men focus on are the loss of hunting dogs and the decline in some game stocks, primarily moose and roe deer. The presence of wolves forces them to hunt less and in other places than they usually do. Knowing the affectionate relationship between hunters and their dogs, and the tremendous amount of time (and money) many hunters invest in training dogs, it is no surprise that the wolves are not popular. Indeed, the typical Scandinavian hunting methods which entail the use of untethered dogs are now seen as impossible in areas with wolves. Since many hunters regard the cooperation with the dog as more important and rewarding than the actual kill (Krange and Skogen 2003), the loss of this form of hunting is all the more aggravating.

These men are strongly attached to their community and to the land. In several respects they keep up a traditional way of living that has been typical for men in rural areas, which entails largely manual work and a somewhat rough contact with nature. They are firmly rooted in what we might term a production-oriented culture; cultural forms that are typical of workers and farmers, comprising high valuation of practical work, technical ingenuity and masculine toughness, and scepticism towards academic knowledge and intellectual pursuits (Willis I977; I979; Dunk I99I; I994; Skogen 200I).

The hunters are just as angry at environmentalists and wildlife biologists (roughly perceived as the same group) as at the predators themselves. They feel that city people generally have far too much power, and are now using this power to turn rural Norway into a game preserve. Due to ignorance and indifference on the part of powerful organisations and government agencies based in urban areas, the voices of local people are not heard.

Underlying such views is an experience of being subject to patronising attitudes from people who do not know Stor-Elvdal, and that lay knowledge about nature is not taken seriously. Seen in this perspective, the dominant discourse of carnivore protection is a typical instance of middle-class efforts to shape and correct the opinions and attitudes (indeed way of life) of working-class people (Dunk 1994; Skogen I996).

\section{All the rest}

The main focus in this article shall remain on the carnivore adversaries. What we want to understand is the element of the social dynamics of carnivore resistance that has to do with symbolic construction of community. But it is essential to keep 
in mind that a considerable number of people in Stor-Elvdal do not engage in the wolf issue, and quite a few have welcomed the wolves. The same was found in an earlier study in another high conflict area in the same region (Skogen 200I). Lack of interest in the issue seems evenly distributed among people who are not directly affected, although young people seem more likely to belong in this category than older people. Pro-wolf attitudes also seem more common among younger people, but here we can also see a distinct effect of higher education. There is a marked tendency that the educated middle class generally takes a more positive view of the carnivores, something which is in accordance with numerous studies of the impact of class on environmental orientation (Cotgrove and Duff i980; Morrison and Dunlap 1986; Eckersley I989; Kriesi 1989; Skogen I996; Strandbu and Skogen 2000). The operative mechanisms that affect middle-class attitudes towards large carnivores have been discussed elsewhere (Skogen 200I). Higher education, which entails some degree of socialisation into a scientific knowledge system and the cultural forms that go with it, also seems to carry weight among people who are directly affected by the presence of large carnivores, such as land owners and hunters. Those who identify with academic knowledge and a scientific discourse, tend to be more positive toward the wolves, even if their direct interests are negatively affected. To the extent that they want to reduce the number of wolves in their own area, they usually build complex arguments in order to explain why this is ecologically feasible (Krange and Skogen 200I).

Although the following discussion will concentrate on the wolf opposition, we will eventually see that these less dedicated groups do not escape the symbolic construction of community.

\section{A sense of community}

Despite the differences between them, sheep farmers, hunters and landowners talk not only about the practical problems the predators cause but also about general issues such as declining quality of life due to people's fear of wolves. It is frequently claimed that a principal asset of life in rural areas, namely outdoor recreation, is seriously devalued because many people are afraid to go for walks, and especially to take their dogs out. There is a particular concern for small children who are allegedly not allowed to play outdoors alone anymore. Elderly people, especially women, are seen as another strongly affected group. By picturing 'weak groups' as vulnerable to dangers that are imposed upon the community from outside, they emphasise that wolf protection is cruel and inhuman. It represents an infringement on the community, and is in effect an assault on the 'weakest among us'.

Furthermore, problems that mainly affect certain groups are frequently presented as serious concerns for the community as a whole. This is done not only by those who experience a particular problem, but by other groups as well. For example, the hunters whose chief concerns are dwindling game stocks and attacked dogs often point out the problems experienced by landowners who lease the hunting they have to pay for. Moreover, sheep owners, a formerly anonymous group that few people paid attention to, are now heralded as vanguard defenders of rural lifestyles and the very habitation of marginal areas. 


\section{Contested knowledge}

Earlier research has indicated that rival knowledge systems play an important part in shaping the carnivore conflicts. Schisms originating from the tension between scientific knowledge and lay, tacit knowledge will overlap and merge with conflicts stemming form tensions between hegemonic and subordinate cultural forms. Such overlap is not perfect, but hegemonic cultural forms generally coincide with or subsume scientific forms of knowledge, as opposed to subordinate cultural forms within which practically founded knowledge holds a pivotal position. Working-class hunters constitute one group that exercises cultural resistance through actively defending practical experience and ridiculing academic knowledge and scientists (see Willis 1977; 1979), represented first and foremost by wildlife biologists and nature managers. They even accuse them of dishonesty and manipulation (Skogen 200I; 2003). The present analysis expands this picture, as all groups of carnivore sceptics claim that local knowledge is generally ignored by those in power, whether they are politicians, managers, biologists or conservationists. However, such claims expressed in more measured terms by the landowners, who are often well-educated and thus more loyal to scientific discourse. The same applies to quite a few of the sheep-herders, who, as we have seen, are not always traditional local farmers. These people express a considerable ambivalence towards scientific knowledge, for example regarding the sizes of carnivore populations. It is obviously important for them to show that they are in no way ignorant, while at the same time defending local and practical knowledge in the face of what they, too, perceive as ridicule. Thus, they join the working-class hunters in constructing a boundary around the local community within which antagonistic forms of knowledge are important elements. Local knowledge is pictured as common to the people who make up the community, and fundamentally different from the hegemonic external knowledge which legitimates the perceived assaults on rural economy and 'the rural way of life'.

\section{A threatened rustic life}

Which common threats are faced by the groups that make up the anti-carnivore alliance? In a sense they find themselves in the same boat, albeit in very different ways, as people who stand to loose from urban expansion and related economic and cultural changes. We also see here an example of cultural commonality between the working class and the proper bourgeoisie; the defence of material production - and associated values - against the cultural expansion of the modern middle class, entailing, among other undesirable things, extensive nature protection based on a romantic view of nature; nature seen as delicate and vulnerable, always threatened by human activities (i.e. the activities pursued by the working class, farmers and landowners) (Skogen, I998; I999). Also, the new middle class may be seen as the culprit behind the mass of regulations interfering with every conceivable aspect of human existence, not least private enterprise, and here elements of working-class and 'bourgeois' culture tend to converge.

Landowners, farmers and working-class hunters all talk about 'our' way of life as threatened by current carnivore management and maintain that the presence of wolves in particular is seriously disturbing the ways 'we' use the land. This is clearly 
not a simple reflection of common lifestyles and land use practices, as these are rather different. Furthermore, the ways these groups use the land may indeed come in conflict with each other, and to some extent even reflect antagonistic economic interests - as is the case with landowners who want to maximise their profits from hunting, and the local working-class hunters who have to pay for it. There are similar conflicting interests criss-crossing the social landscape between all three groups.

However, cultivation of rusticity as a defence against urban expansion (physical and cultural) appears to be a common identity factor, despite cultural and economic differences. This rusticity is constructed in different ways, as exemplified by the contrast between oilskin raincoats and Land rovers on the one hand, and baseball caps and Japanese pick-up trucks on the other. All varieties of rustic lifestyle may be exposed to threats due to current processes of social change, although lifestyles based in different class positions will not be affected in the same way - nor necessarily by the same aspects of social change. The appearance of wolves may then be seen as a symbol of changing value orientations in 'society at large', and these changes may be tied to the more tangible changes that rural people experience in their everyday lives.

Bell (I994) provides a very convincing account of 'construction of community' in an English village with substantial in-migration of wealthy urbanites and a population generally characterised by both old and new class antagonisms. Among Bell's important insights we find an explication of the role of nature as substitute for class as a source of identity, indeed as a source of morality. Nature escapes the problematic aspects of class which trouble Bell's informants. Although they recognize the continued significance of class in most areas of life (and this is irrespective of their own social position), they claim that this is a deplorable state of affairs. By seeking refuge in the concepts 'nature' and indeed 'rurality' as significant elements in their identity projects, they are able to construct a sense of collectivity which - at least at one symbolic level - overrides the blatant material inequality and large cultural differences that otherwise mark the village. Seeking and defending nature, and emphasising a fundamental antagonism between rural and urban life, will let wealthy urban in-migrants as well as the old 'landed gentry' slip away from confrontations over their material privileges and political power, and may at the same time provide the rural working class with components for identity construction that downplay their material and political deprivation. This perspective would seem to fit our observations in Stor-Elvdal almost perfectly, although - as we shall see later - the issue of class is perhaps swept under the carpet even more effectively than in Bell's English village.

A common rejection of cities and urban people prevail among the carnivore resisters in Stor-Elvdal. This is most prominent among the hunters, and we will use their archetypal account as a starting point. Most of them can tell horror stories about how they themselves, or some of their friends, have been harassed and almost mugged when visiting Oslo. Large cities are unsafe, chaotic, noisy, and packed with social misery. They emphasise the negative aspects of the city as a physical structure - big ugly houses, crowded streets, and, most importantly, absence of nature. The hunters see the qualities of the rural community and its natural surroundings as a dramatic contrast to the chaotic and unpleasant nature of the city; and their own lives as rural people and outdoorsmen as a negation of city life. 
A pivotal element in the hunters' general interpretation of their situation is that they are up against powerful enemies that do not understand - or are oblivious to - the consequences of current land use regimes. They describe them as 'city people' and 'extremists'. Consequently, the appearance of wolves is associated with cities and an urban conception of nature. In their minds, that is a romantic view based on a dreamlike glorification of untouched nature, and it does not pay heed to actual consequences for real people. Through this construction, the wolf becomes an icon of urbanity. In the hunters' world, that is the ultimate antagonism of the life they love. The wolves thus symbolise attacks on the community not from encroaching wilderness, as on might believe, but from cities. And that is why it is doubly important to reinforce the symbolic defence line, so that the arch-enemies are held at bay at all costs.

Varieties of this interpretation are found in the two other groups as well, however not as unanimous, and generally not as strong. One should perhaps think that farmers would be among the most anti-urban, but as we have seen, not all Stor-Elvdal sheep owners are typical farmers. Some are, though, and anti-urban views identical to those of the hunters are not uncommon. But there are also some who actually have an urban background themselves, or who have higher education, or both. This appears to modify the anti-urban sentiments, but not eradicate them. Similarly, as we have seen, many of the landowners are educated at universities, and they also have strong ties to cities. That is, not only through their economic activities or networks from the university days; they generally have many close relatives living in cities. In fact, most of the large forest properties in the entire region were taken over by urban speculators in I870's, due to a dramatic fall in timber prices which drove the old proprietors bankrupt. Some of the incoming families did not settle permanently in the valley until the I920s. Thus, few landowners have more than a few generations of roots in the area, and retain a big family network - which is generally also economically involved - in cities.

But even so, sheep farmers and landowners join the working-class hunters in their lamentation of cities and urban life and in their conception of urban expansion - physically, economically and culturally - as a threat to a rural life form perceived as common to them all. The parallels to Bell's (I994) account form the British countryside are striking. Not only will this 'unification' and boundary demarcation let them confront 'the enemy' in a more efficient manner, it will also take their own minds off the troubling schisms between them; tensions that from time to time break out in disturbing forms of open conflict.

\section{Ambivalence and class conflict}

Ambivalence seems to be a theme running through the alliance and underpinning the flexible way in which its basic perspectives are handled. As we have already seen, well-educated people who are negatively affected by the wolves struggle to maintain a delicate balance between urban modernity and academia on the one side, and rusticity and identification with 'indigenous' local knowledge on the other.

Another form of ambivalence is inherent in the mixed feelings most informants seem to have towards other groups within the alliance. This is evident within all of the three categories. These (manifest or latent) conflict lines converge with class boundaries to a significant extent, but by no means entirely so. For example, although we have focused on local hunters rooted in a working-class culture, not all 
hunters belong to the working class. Practically all the big landowners are hunters too, and in that capacity, they see the world through hunters' eyes. But this is not their primary interest, nor a primary source of identity.

Some sheep herders tell stories about how grazing agreements have been discarded almost without notice because landowners wanted to give priority to wild game, in order to earn more money from hunting, or even because they wanted to take up a little sheep herding themselves - possibly more as a hobby than anything else. In general, the small sheep farmers seem uneasy with the dependence on the goodwill of larger landowners that some of them are subject to. Some have formal grazing rights on property that is not their own, but those who do not are in a vulnerable position, obviously reminding some informants of a time when class antagonism was more blatant than today.

Some landowners admit that they are sceptical of sheep herding on the present scale - or at least that they used to be, until the wolves arrived. The main reason for this is conflicts with hunting - not only their own, but that of people they want to see hunting on their property and paying for it. Although competition between sheep and wild game for grazing resources has been presented as a problem in some other contexts, this received little attention in our interviews. What bothers the landowners is the massive presence of the sheep themselves, as well as sheep dogs and people looking after sheep, in the hunting season. This disturbs the game, distracts the hunting dogs and necessitates extra safety precautions on the part of the hunters. Consequently, some informants state openly that they see the sheep owners principally as tactical allies.

The working-class hunters are obviously vulnerable to further commercialisation of hunting, and here lays a conflict of interest vis-à-vis the landowners, which is in a sense 'objective'. Access to small-game hunting is still good (and cheap) in the region, and even moose hunting is available to most locals - even though the prices are seen as rather steep by some informants. There is a strong drive towards more market orientation among some large landowners, however, and although there is still enough for everybody, some hunter informants are troubled about the outlook for the future. They are well aware of the development, and some do not hesitate to label the landowners greedy and selfish. The landowners' alleged lack of engagement in local economic development is also mentioned in this connection, as an illustration of their deficient social conscience.

There seem to have been few skirmishes between hunters and sheep owners in Stor-Elvdal, something which may perhaps be attributed to the relatively low density of sheep. It is known from other parts of Norway that hunters have clashed with sheep owners over several issues. One such issue is hunting dogs chasing sheep, and another is the practice of letting sheep graze near roads and railways (and when they are inevitably run over, experienced hunters are appointed to put them out of their misery). However, the Stor-Elvdal hunters had not been very aware of the sheep owners and their problems until the wolves arrived. Bears have caused problems for livestock herders in the region much longer than the wolves, and they actually forced some sheep farmers to give up rough grazing before a single wolf was spotted. But the bears are not a problem for hunters, and some informants admit that they have only recently discovered the true anguish of the sheep owners - but claim that they will never again forget it, even if the wolves should eventually disappear. 
In general, the impression is that there is limited contact between the three groups; we might say that there is limited contact across class boundaries. There are, however, some notable exceptions. One is a particular type of relationship between a few workingclass hunters and 'public-minded' landowners, where the former are recognized as expert hunters, and receive different types of favours in return for helping with hunting matters. They also do odd bits of work for the landowners, mostly related to land management in some way or another. Whereas these relationships seem to be genuinely cordial on one level, they nevertheless have 'master-serf' written all over them. Another example is the contact between landowners and sheep-owners in the landowners' capacity as farmers and in the sheep owners' capacity as foresters. Although farming means very little economically to the larger landowners, some of them do farm. Some sheep-owners also own forest properties, although they are generally small or have marginal productivity. Thus, there is a farming-and-forestry community of sorts, associated with farming or forestry organisations, and the promotion of farming and forestry interests vis-à-vis local authorities, and so on. However, social contact seems to be limited, and in some cases to be moulded in the same form as the relationship between working-class hunters and big landowners.

Bell (I994) found that class was an omnipresent, yet disturbing, factor in everyday life in his English village. In Stor-Elvdal, the existence of class boundaries is largely rejected by all our carnivore adversaries (and by many other informants in the study). Interestingly, it is the absence of cultural, not economic, class differences that is emphasised, and held up as a contrast to 'earlier times'. Everybody, including the land-owning local bourgeoisie, talk about the huge differences and impenetrable boundaries that used to exist. But now everybody are buddies, more or less. Quite a few (but far from all) of our working-class informants speak of the younger generations of landowners as ordinary people, just like anybody else. They coach children's football teams, chat cordially when they are out shopping, invite people into their kitchen to discuss hunting, and so on. The fact that they own huge properties, live in big houses and drive Jaguars, is seen as irrelevant and rarely commented upon. So even though the inequality in wealth prevails, the important thing seems to be that the landowners have changed their style. Conversely, the landowners tell about how difficult it used to be for rich kids to get accepted by the large majority of school mates who were 'regular folk', and how tough it was to be socially isolated as a child. But all this has changed now, too, and there are no barriers between children from different backgrounds anymore.

The important thing here is not that this picture is extremely different from the impression we get as observers from outside, which is that of an exceptionally visible class structure. Rather, we should notice that there is a common propensity to construct such a vision of community, by downplaying contrasts that are obvious not only to visiting researchers, but also to many in-migrants in Stor-Elvdal. Maybe the common resort to nature and rurality as sources of community, or collective identity, has been even more efficient here than in Bell's village. Maybe there are even some cultural differences between Norway and England regarding the acceptability of the word 'class'. It could be more unacceptable to recognize class as an organising principle in purportedly egalitarian Norway than it is in Britain, which has a reputation as a 'class society' (Bell I994). However, it is important to bear in mind that the loggers and mill workers in Østerdalen traditionally have been among the 
most militant in the Norwegian labour movement. One of Stor-Elvdal's neighbouring municipalities had a mayor from the Communist party as late as the I96os. So it is not like 'class' has been absent from local discourses for a very long time.

\section{More ambivalence: a basis for enlisting the neutrals}

If we return briefly to the people who have a relatively positive attitude towards the carnivores, including wolves, it is interesting to observe that many of them share the view that current nature management, and indeed carnivore management, is centralised and far removed from the communities that are affected by management actions. Even educated middle-class people who generally sympathise with conservation and who may see the wolves as an interesting addition to local nature (indeed as a symbol not of cities but of wilderness), often subscribe to the view that local knowledge and local interests are ignored by powerful actors located outside the community. They easily pick up on the same rhetoric as the carnivore adversaries, particularly emphasising the pressure from 'society at large', yet without drawing the same conclusions regarding the animals themselves. This seems to indicate that even people who have a positive view of the large predators, and who may be generally supportive of current management objectives, are quite prepared to construe management agencies and management practices as malevolent outside forces. By the same token, they accentuate their bonds to local groups that disagree with them on the carnivore issue, but who are seen primarily as fellow community members. They are prepared to take part in the symbolic construction of boundaries between 'inside' and 'outside' the community. If they somehow had to choose between wolves and 'community', it seems obvious that most of them would choose the latter, and willingly take part in its defence; symbolic or otherwise.

\section{Conclusion}

What we have seen here is that different factions within the anti-carnivore front approach the notion of 'community' from different angles, adjusting it to their own perspective. They also endeavour to enlist 'the neutrals' as community defenders, an effort which has been moderately successful, and which appears to have a substantial further potential.

This is in line with the theoretical positions we presented at the beginning of the paper, and seems to support the assumption that symbolic construction of community as a theoretical framework is indeed helpful in understanding important aspects of the carnivore conflicts. It appears that these conflicts (their tangible material core notwithstanding) to a considerable extent entail tensions derived from processes of more general social change, and that symbolic construction of community could be seen as part of a cultural line of defence against several forms of perceived danger from outside. That tensions are also found between the different groups in the anti-carnivore alliance does not mean that their sense of community is 'faked' or 'artificial', it just means that it is obviously something that has to be worked on, that is, constructed, and that it is not simply a mechanical reflection of common material interests.

This paper may be seen as a contribution to the literature that analyses the carnivore conflicts, and land use conflicts in general, as something more than clashes 
between 'interest groups'. Although inadequately reflected in the public debate and in public policies, it is increasingly evident that these conflicts reach much further. This will also have implications for policymaking and management strategies. We cannot go deeply into such implications here, but suggest that avoiding strategies that underpin the tension between rural lifestyles and cultural forms, and hegemonic urban - cultural forms that are associated with problematic modernisation processes, should be among the more obvious ones.

\section{Notes}

I A few sessions were conducted with couples and some in the form of focus groups, the latter particularly with the youngest informants, who are often easier to 'get going' in a group setting.

\section{References}

Bell, M. M. (I994) Childerley. Nature and morality in a country village (Chicago: University of Chicago Press)

Cohen, A.P. (I985) The symbolic construction of community (London: Routledge)

Cotgrove, S. and A. Duff (I980) Environmentalism, middle-class radicalism and politics. Sociological Review 28 pp. 333-35I

Crow, G. and G. Allan (I994) Community life. An introduction to local social relations (London: Harvester Wheatsheaf)

Douglas, M. (I992) Risk and blame. Essays in cultural theory (London: Routledge)

Douglas, M. and A. Wildavsky (I982) Risk and culture (Berkeley: University of California Press)

Dunk, T.W. (I99I) It's a working man's town. Male working-class culture (Montreal and Kingston: McGill-Queen's University Press)

Dunk, T.W. (I994) Talking about trees: Environment and society in forest workers' culture. Canadian Review of Sociology and Anthropology 3I pp. I4-34

Eckersley, R. (1989) Green politics and the new class: Selfishness or virtue? Political Studies 36 pp. $205-223$

Gupta, A. and J. Ferguson eds. (1997) Culture, power, place (Durham: Duke University Press)

Krange, O. and K. Skogen (200I) Naturen i Stor-Elvdal, ulven og det sosiale landskapet. En kortrapport fra prosjektet Konfliktlinjer i utmarka. NOVA Temahefte I/OI, Oslo:NOVA.

Krange, O. and K. Skogen (2003) Skudd i løse lufta. Unge jegere og rovdyrpolitikken. Pp 255-283 in F. Engelsta and G. Ødegård eds., Ungdom, makt og mening (Oslo: Gyldendal Akademisk)

Kriesi, H. (I989) New social movements and the new class in the Netherlands. American Journal of Sociology 94 pp. Iо78-іпा6

Kleese, D. (2002) Contested natures: wolves in late modernity. Society and Natural Resources I5 pp. 313-326

Liepins, R. (2000) New energies for an old idea: reworking approaches to 'community' in contemporary rural studies. Journal of Rural Studies I6 pp. 23-35

Morrison, D.E. and R.E. Dunlap (I986) Environmentalism and elitism: A conceptual and empirical analysis. Environmental management Io pp. 58I-589

Nelson, P. B. (200I) Rural restructuring in the American West: land use, family and class discourses. Journal of Rural Studies I7 pp. 395-407

Skogen, K. (1996) Young environmentalists: Post-modern identities or middle-class culture? Sociological Review 44 pp. $452-73$

Skogen, K. (I998) A Touch of Class. The Persistence of Class Cultures among Norwegian Youth. The Nordic Journal of Youth Research 6 (2) pp. I7-37 
Skogen, K. (1999) Another Look at Culture and Nature. How Culture Patterns Influence Environmental Orientation among Norwegian Youth. Acta Sociologica 42 pp. 223-239

Skogen, K. (200I) Who's afraid of the big, bad wolf? Young people's responses to the conflicts over large carnivores in Eastern Norway. Rural Sociology 66 pp. 203-226

Skogen, K. (2003) Adapting Adaptive Management to a Cultural Understanding of Land Use Conflicts. Society and Natural Resources I6 pp. 435-450

Strandbu, A. and K. Skogen (2000) Environmentalism among Norwegian youth - Different paths to attitudes and action? Journal of Youth Studies 3 pp. I89-209

Willis, P. (I977) Learning to labour (Aldershot: Gower)

Willis, P. (I979) Shop floor culture, masculinity and the wage form. Pp. I85-198 in J. Clarke and C. Critcher eds., Working class culture (London: Hutchinson)

Ketil Skogen

NOVA - Norwegian Social Research

Oslo, Norway

and

Norwegian Institute for Nature Research (NINA), Unit for Human-Environment Studies,

Lillehammer, Norway

Olve Krange

NOVA - Norwegian Social Research

Oslo, Norway 